\title{
FAKTOR-FAKTOR YANG BERHUBUNGAN DENGAN PENGGUNAAN ALAT PELINDUNG DIRI PADA PETANI PENGGUNA PESTISIDA
}

\author{
Factors Related To The Usage Of Appliance Protector Of Self On Farmers Use \\ of Pesticides
}

\author{
Ridha Hayati1, Kasman², Raudatul Jannah ${ }^{3}$ \\ 1,2,3 Universitas Islam Kalimantan Banjarmasin \\ Email: Hafizulya22@gmail.com
}

\begin{abstract}
ABSTRAK
Alat pelindung diri merupakan salah satu cara yang dapat digunakan tenaga kerja untuk melindungi sebagian atau seluruh tubuhnya dari adanya potensi bahaya atau kecelakaan kerja. Penelitian ini bertujuan untuk menganalisis faktor-faktor yang berhubungan dengan penggunaan alat pelindung diri pada petani pengguna pestisida di desa Candi Laras. Metode penelitian yang digunakan adalah penelitian observasional analitik, dengan pendekatan cross sectional. Populasi dalam penelitian ini adalah seluruh petani yang ada di Desa Candi Laras yang berjumlah 378 orang dengan jumlah sampel sebanyak 80 orang. Data dianalisis dengan uji chi square. Teknik pengambilan sampel accidental sampling. Instrumen yang digunakan dalam penelitian adalah kuesioner. Hasil penelitian menunjukkan $85 \%$ pengetahuan petani baik, 96,25\% sikap petani positif, 58,75\% status ekonomi petani rendah, 77,5\% masa kerja lama $>3$ tahun dan 37,5\% petani menggunakan alat pelindung diri. Hasil analisis bivariat menunjukkan bahwa tidak ada hubungan antara pengetahuan dengan penggunaan alat pelindung diri $(\mathrm{p}=0,194)$, tidak ada hubungan antara sikap dengan penggunaan alat pelindung diri $(\mathrm{p}=0,288)$, ada hubungan antara status ekonomi dengan penggunaan alat pelindung diri $(p=0,002)$, dan tidak ada hubungan antara masa kerja dengan penggunaan alat pelindung diri $(p=0,678)$. Petani hendaknya selalu menggunakan alat pelindung diri secara lengkap, perlu adanya penyuluhan/pelatihan kepada petani tentang manfaat dari penggunaan alat pelindung diri dan bahaya yang dapat ditimbulkan akibat tidak menggunakan alat pelindung diri.
\end{abstract}

Kata Kunci : Pengetahuan, sikap, masa kerja, status ekonomi dan penggunaan alat pelindung diri

\section{ABSTRACT}

Appliance protector of self is one way that can be used manpower to protect part or the entire body of their potential danger or accident. This study aimed to analyze the factors associated with the use of appliance protector of self at the farmers' pesticide applicators in the village of Candi Laras. The method used is an analytic observational study with cross sectional approach. The population in this study were all farmers in the village of Candi Laras totaling 378 people with a total sample of 80 people. Data were analyzed with chi square test. The sampling technique accidental sampling. Instruments used in the study was a questionnaire. The results showed 85\% good knowledge of farmers, farmers 'attitudes positive 96.25\%, $58.75 \%$ lower farmers' economic status, $77.5 \%$ long working life of $>3$ years and $37.5 \%$ of farmers use appliance protector of self. Results of bivariate analysis showed that there is no relation between knowledge and the use of appliance protector of self $(p=0.194)$, there was no relationship between attitudes to the use of appliance protector of self $(p=0.288)$, there is a relationship between economic status with the use of appliance protector of self $(p=0.002)$, and there is no relationship between tenure with the use of appliance protector of self $(p=0.678)$. Farmer shall always use appliance protector of self is complete, the need for education / training to farmers about the benefits of the use of appliance protector of self and the hazards that can be caused by not using appliance protector of self.

Keywords : Knowledge, attitudes, employment, economic status and use of appliance protector of self

\begin{tabular}{lll}
\hline Sekretariat & \multicolumn{2}{l}{ Article History: } \\
Editorial: Kampus FKM UNISMUH PALU - Palu 94118, & $\Rightarrow \quad$ Received 24 Februari 2018 \\
$\quad$ Sulawesi Tengah, Indonesia & $\Rightarrow$ & Revised 13 Maret 2018 \\
Telp/HP: +6281245936241, Fax (0451) 425627 & $\Rightarrow$ & Accepted 17 April 2018 \\
E-mail: jurnal.mppki@gmail.com & $\Rightarrow$ & Available online 25 Juni 2018 \\
OJS: http://jurnal.unismuhpalu.ac.id/index.php/PJKM & &
\end{tabular}




\section{PENDAHULUAN}

Penggunaan pestisida dalam suatu lahan pertanian diharapkan mampu meningkatkan hasil pertanian serta dapat membuat biaya pengelolaan pertanian menjadi lebih efisien dan ekonomis (Afrianto, 2014). Namun dalam perkembangannya, penggunaan pestisida pada petani cenderung bukan atas dasar untuk mengendalikan hama namun menjalankannya dengan cover blanket system yaitu suatu sistem dimana ada ataupun tidaknya hama, tanaman akan tetap disemprot dengan menggunakan pestisida (Prijanto, 2009).

Penggunaan pestisida yang tidak bijaksana dapat menimbulkan berbagai dampak negatif, salah satunya ialah keracunan. Keracunan pestisida pada petani terkait dengan beberapa faktor antara lain faktor dari dalam tubuh (internal) dan dari luar tubuh (eksternal). Faktor dari dalam tubuh antara lain umur, jenis kelamin, genetik, status gizi, kadar hemoglobin, tingkat pengetahuan dan status kesehatan. Sedangkan faktor dari luar tubuh mempunyai peranan yang besar. Faktor tersebut antara lain banyaknya jenis pestisida yang digunakan, jenis pestisida, dosis pestisida, frekuensi penyemprotan, masa kerja menjadi penyemprot, lama menyemprot, pemakaian alat pelindung diri, cara penanganan pestisida, kontak terakhir dengan pestisida, ketinggian tanaman, suhu lingkungan, waktu menyemprot dan tindakan terhadap arah angin (Aprinias, 2009).

Menurut lembaga kesehatan dunia (WHO), keracunan yang disebabkan oleh pestisida dapat membunuh 355.000 orang di seluruh dunia setiap tahunnya. Menghindari bahaya keracunan pada saat penggunaan pestisida hendaknya petani menggunakan Alat Pelindung Diri (APD).

Namun dalam hal ini Djojosumarto (2008) mengatakan bahwa petani pengguna cenderung menganggap enteng bahaya pestisida sehingga mereka tidak mematuhi syarat-syarat keselamatan dalam penggunaan pestisida termasuk di dalamnya menggunakan alat pelindung diri. Keracunan pestisida yang sering tidak terasa dan akibat yang sulit diramalkan mendorong mereka untuk tetap mengaplikasikan pestisida dengan cara mereka karena tidak merasa terganggu (Sularti, Muhlisin A,
2012).

Candi Laras merupakan sebuah Desa yang terletak di Kecamatan Candi Laras Selatan Kabupaten Tapin, mempunyai jumlah penduduk secara keseluruhan sebanyak 1165 jiwa, yang terdiri dari 593 perempuan dan 572 laki-laki dengan jumlah kepala keluarga sebanyak 388 jiwa dan sebanyak 378 jiwa berprofesi sebagai petani. Berdasarkan survei pendahuluan diketahui 3 dari 8 petani merokok saat menyemprot dengan pestisida, dan beberapa petani merasakan panas akibat keteledoran dalam mengaplikasikan pestisida, bahkan ada yang pingsan setelah selesai menyemprot dengan pestisida. Dari uraian tersebut, peneliti ingin melakukan penelitian mengenai "Faktor-faktor yang berhubungan dengan penggunaan alat pelindung diri pada petani pengguna pestisida".

\section{METODE PENELITIAN}

Penelitian ini dilakukan di Desa Candi Laras Kecamatan Candi Laras Selatan Kabupaten Tapin, pada bulan Mei-Agustus 2016. Dengan menggunakan jenis penelitian analitik yaitu menghubungkan variabel bebas dengan variabel terikat. Rancangan penelitian ini menggunakan pendekatan cross sectional. Populasi dalam penelitian ini adalah semua petani yang berada di Desa Candi Laras sebanyak 378 jiwa, besar sampel penelitian ditentukan dengan menggunakan rumus dan mendapatkan sampel sebanyak 80 orang. Teknik pengambilan sampel menggunakan teknik accidental sampling yaitu dengan mengambil responden yang kebetulan ada dan bersedia.

\section{HASIL}

Data responden paling banyak berumur antara $\leq 40$ tahun, yaitu sebanyak 52 orang atau $65 \%$. Pendidikan responden yang paling banyak adalah SD yaitu sebanyak 31 orang atau 38,75\%, Penggunaan APD Berdasarkan hasil penelitian didapatkan hasil bahwa lebih banyak responden yang tidak menggunakan APD yaitu sebanyak 50 responden atau $62,5 \%$. Penggunaan APD yang paling sering digunakan responden adalah pakaian pelindung $(98,75 \%)$ dan penutup kepala (90\%), alasan responden sering menggunakan pakaian pelindung dan penutup kepala ialah untuk melindungi diri dari sengatan matahari. APD yang jarang 
digunakan responden ialah sepatu boot (53,75\%), alasan responden jarang menggunakan sepatu boot ialah karena kondisi tanah yang terkadang becek, sedangkan penggunaan APD yang paling sedikit digunakan ialah celemek (5\%) dan pelindung mata dan muka $(7,5 \%)$, alasan responden tidak menggunakan ialah karena mereka tidak mengetahui bentuk dan fungsi APD tersebut untuk apa saat mereka bekerja dengan pestisida.

Dari hasil penelitian didapatkan hasil bahwa responden mempunyai pengetahuan yang baik tentang APD sebanyak 68 atau $85 \%$ dan responden yang mempunyai pengetahuan cukup tentang APD sebanyak 12 orang atau $15 \%$. Pengetahuan responden baik umumnya berkaitan dengan pengetahuan tentang bagaimana cara menyemprot yang baik dan benar, waktu dan cuaca yang paling baik saat menyemprot serta gejala dari keracunan pestisida. Namun demikian, responden kurang mengetahui alat pelindung diri yang sebaiknya digunakan ketika bekerja dengan pestisida.

Sikap dari hasil penelitian didapatkan hasil bahwa 3 responden $(3,75 \%)$ memiliki sikap negatif dan 77 responden $(96,25 \%)$ memiliki sikap positif. Responden setuju dengan pernyataan bahwa sebelum menggunakan pestisida hendaknya membaca terlebih dahulu petunjuk pemakaian, penggunaan pestisida yang sesuai dosis, dan yang terdaftar di Indonesia serta tidak kadaluarsa. Alasan responden setuju dengan pernyataan tersebut ialah karena jika mereka menggunakan pestisida berlebih dan tidak sesuai dosis mereka khawatir hama dan tanaman penganggu yang ingin mereka singkirkan justru tidak akan mati. Responden juga setuju dengan pernyataan bahwa pakaian pelindung, celemek, penutup kepala, pelindung mata dan muka, sarung tangan, masker, dan sepatu boot merupakan alat pelindung diri yang harus dipakai ketika menggunakan pestisida karena penggunaan alat pelindung diri tersebut dapat mencegah terjadinya kecelakaan kerja.

Status ekonomi, berdasarkan hasil penelitian didapatkan hasil bahwa 47 responden $(58,75 \%)$ memiliki status ekonomi rendah dan 33 responden $(41,25 \%)$ memiliki status ekonomi tinggi.Responden dalam penelitian ini sebagian besar memiliki status ekonomi yang rendah, adapun responden yang memiliki status ekonomi tinggi, sebagian besar dari mereka memiliki pekerjaan sampingan sebagai buruh kelapa sawit, sehingga pendapatan perbulan mereka lebih tinggi dibandingkan dengan petani biasa.

Masa Kerja Berdasarkan hasil penelitian didapatkan hasil bahwa 18 responden $(22,5 \%)$ memiliki masa kerja baru $\leq 3$ tahun sebagai petani, dan 62 responden $(77,5 \%)$ memiliki masa kerja lama $>3$ tahun sebagai petani. Berdasarkan wawancara, petani di Desa Candi Laras merupakan penduduk asli yang sudah mulai bertani sejak mereka memasuki usia remaja. Sehingga kebanyakan dari mereka mempunyai masa kerja yang lama.

\section{PEMBAHASAN}

Dari hasil penelitian $(p=0,194)$ menunjukan bahwa tidak ada hubungan antara pengetahuan dengan penggunaan APD pada petani pengguna pestisida di Desa Candi Laras (Lihat lampiran, tabel 1). Hasil ini tidak sejalan dengan penelitian oleh Reza Yuda Kusuma tahun 2013 tentang hubungan antara pengetahuan, sikap, dan kenyamanan dengan penggunaan alat pelindung wajah didapatkan hasil bahwa ada hubungan antara pengetahuan dengan penggunaan alat pelindung wajah. Berdasarkan hasil penelitian didapatkan bahwa responden yang memiliki pengetahuan cukup tentang APD sebanyak 12 orang, 10 orang atau $83,3 \%$ diantaranya tidak menggunakan APD. Rata-rata dari mereka hanya mengetahui tentang bagaimana cara menyemprot yang baik, tetapi mereka tidak mengetahui seperti apa jenis APD yang sebaiknya digunakan ketika bekerja dengan pestisida.

Responden yang memiliki pengetahuan cukup tentang APD sebanyak 12 orang, dan 2 orang atau 16,7\% diantaranya menggunakan APD lengkap. Responden tahu bahwa alat pelindung diri yang baik itu terdiri dari pakaian pelindung, celemek, penutup kepala, pelindung mata dan muka, sarung tangan, masker dan sepatu boot dan pada praktiknya mereka mengaplikasikan apa yang mereka ketahui. Sebanyak 68 responden yang memiliki pengetahuan baik tentang APD, 40 orang atau 83,3\% diantaranya tidak menggunakan APD. Penge- 
tahuan yang baik jika tidak didukung oleh perilaku untuk menerapkan pengetahuannya tersebut hanya akan menjadi sia-sia. Responden yang memiliki pengetahuan baik tentang APD sebanyak 68 orang, dan 28 orang atau $41,2 \%$ diantarany menggunakan APD lengkap. Meskipun rata-rata pendidikan responden adalah SD, tetapi rata-rata dari mereka mempunyai masa kerja yang lama dan sebagian mempunyai status ekonomi yang tinggi.

Berdasarkan hasil penelitian $(\mathrm{p}=0,288)$ menunjukkan bahwa tidak ada hubungan antara sikap dengan penggunaan APD pada petani pengguna pestisida di Desa Candi Laras (Lihat lampiran, tabel 2). Hasil penelitian ini sejalan dengan penelitian yang dilakukan Endro Hari Yulianto tahun 2012, yang meneliti tentang faktor-faktor yang berhubungan dengan penggunaan APD, didapatkan hasil bahwa tidak ada hubungan antara sikap dengan penggunaan alat pelindung diri. Berdasarkan hasil penelitian dapat dilihat bahwa 3 responden memiliki sikap negatif terhadap APD, 3 orang atau $100 \%$ tidak menggunakan APD. Dilihat dari data responden umur mereka masih dalam tahap dewasa muda $\leq 40$ tahun, dimana 2 diantaranya masih berusia 19 tahun. Untuk pendidikan masih tergolong rendah, 2 orang lulusan SD dan satu orang lulusan SMP. Sebanyak 77 responden yang memiliki sikap positif terhadap APD, 47 orang atau $61,0 \%$ diantaranya tidak menggunakan APD. Meskipun 85\% pengetahuan mereka baik, akan tetapi $70 \%$ dari mereka masih bersatus ekonomi rendah. Responden yang memiliki sikap positif terhadap APD sebanyak 77 orang, dan 30 orang atau $39,0 \%$ diantaranya menggunakan APD lengkap. Kebanyakan dari mereka mempunyai masa kerja yang lama dengan status ekonomi yang tinggi.

Berdasarkan hasil penelitian $(p=0,002)$ menunjukkan bahwa ada hubungan antara status ekonomi dengan penggunaan APD pada petani pengguna pestisida di Desa Candi Laras, dengan OR 4,442 (1,691-11,666) artinya responden yang mempunyai status ekonomi rendah cenderung 4 kali lebih berisiko tidak menggunakan APD dibanding responden yang mempunyai status ekonomi tinggi (Lihat lampiran, tabel 3). Berdasarkan hasil penelitian dapat dilihat bahwa 47 responden yang memiliki status ekonomi rendah, 36 orang atau $76,6 \%$ tidak menggunakan APD. Alasan petani tidak menggunakan APD ialah karena tidak mampu untuk membeli APD tersebut. Dari 47 responden yang memiliki status ekonomi rendah, 11 orang atau 23,4\% menggunakan APD lengkap. Meskipun ratarata pendidikan responden adalah SD, tetapi pengetahuan dan sikap mereka terhadap APD tergolong baik, ditambah masa kerja mereka sebagai petani tergolong lama.

Sebanyak 33 responden yang memiliki status ekonomi tinggi, 14 orang atau $42,4 \%$ diantaranya tidak menggunakan APD. Meskipun rata-rata responden memiliki masa kerja yang tergolong lama dengan pengetahuan dan sikap yang baik, hal yang menjadi alasan kenapa mereka tidak menggunakan APD bisa saja karena faktor kebiasaan dan keadaan lingkungan sekitar. Responden yang memiliki status ekonomi tinggi sebanyak 33 orang, dan 19 orang atau 57,6\% diantaranya menggunakan APD lengkap. Berdasarkan hasil wawancara diketahui bahwa responden dengan status ekonomi yang tinggi, kebanyakan dari mereka mempunyai pekerjaan sampingan sebagai buruh kelapa sawit. Yang dimana, pihak kelapa sawit juga telah menyediakan perlengkapan APD bagi mereka yang tidak hanya bisa mereka gunakan saat bekerja sebagai buruh kelapa sawit tetapi juga saat bekerja sebagai petani.

Berdasarkan hasil penelitian $(\mathrm{p}=0,678)$ menunjukkan bahwa tidak ada hubungan antara masa kerja dengan penggunaan APD pada petani pengguna pestisida di Desa Candi Laras (Lihat lampiran, tabel 4). Hasil penelitian ini sejalan dengan penelitian yang dilakukan oleh Wekoyla tahun 2012, meneliti tentang hubungan pengetahuan, sikap, pendidikan, dan masa kerja terhadap perilaku penggunaan APD, didapatkan hasil bahwa tidak ada hubungan antara masa kerja terhadap perilaku penggunaan APD. Berdasarkan hasil penelitian dapat dilihat bahwa 18 responden yang memiliki masa kerja baru $\leq 3$ tahun sebagai petani, 12 orang atau $66,7 \%$ tidak menggunakan APD. Dilihat dari status ekonomi responden rendah, dari segi umur responden rata-rata dari mereka belum mencapai umur 30 tahun dan hanya 1 orang yang berumur 60 tahun. Menurut (Notoatmodjo, 2003) umur mempengaruhi 
daya tangkap dan pola pikir seseorang. Semakin bertambah umur akan semakin berkembang pula daya tangkap dan pola pikirnya, sehingga pengetahuan yang diperoleh semakin banyak. Dari 18 responden yang memiliki masa kerja baru $\leq 3$ tahun, 6 orang atau $33,3 \%$ menggunakan APD lengkap. Dilihat dari segi pendidikan 2 orang lulus SD, 3 orang lulus SMP dan 1 orang lulus SMA, dari segi pengetahuan dan sikap ratarata baik dan positif. Selain itu dari $66,7 \%$ status ekonomi responden tinggi.

Sebanyak 62 responden yang memiliki masa kerja lama $>3$ tahun sebagai petani, 38 orang atau $61,3 \%$ diantaranya tidak menggunakan APD. Meskipun memiliki masa kerja yang lama dan usia yang terbilang matang, ternyata tidak menjadi jaminan bahwa responden mempunyai motivasi yang lebih baik dalam hal penggunaan APD. Robbins (1998) mengemukakan bahwa tidak ada alasan yang meyakinkan bahwa orang-orang yang telah lama berada dalam suatu pekerjaan akan lebih produktif dan mempunyai motivasi kerja yang lebih tinggi dibandingkan dengan orang yang belum lama bekerja. Selain itu alasan responden tidak menggunakan APD secara lengkap ialah karena mereka merasa selama ini baik-baik saja dan tidak ada bahaya yang berarti akibat tidak menggunakan APD. Responden yang memiliki masa kerja lama $>3$ tahun sebanyak 62 orang, dan 24 orang atau 38,7\% diantaranya menggunakan APD lengkap. Meskipun 66,7\% responden hanya lulusan SD, tetapi $62,5 \%$ responden berstatus ekonomi tinggi.

\section{KESIMPULAN DAN SARAN}

Ada hubungan antara status ekonomi dengan penggunaan APD pada petani pengguna pestisida di Desa Candi Laras, serta tidak ada hubungan antara pengetahuan, sikap dan masa kerja dengan penggunaan APD pada petani pengguna pestisida di Desa Candi Laras. Bagi Petani Pengguna Pestisida, hendaknya selalu menggunakan APD secara lengkapsaat hendak menyemprot saja, tetapi juga saat menyiapkan pestisida hingga mencuci peralatan semprot. Bagi Pemerintah, adanya bantuan dana dari pemerintah dalam hal pemberian alat pelindung diri kepada petani. Bagi Instansi, perlu adanya penyuluhan/pelatihan dari instansi terkait, seperti pihak Puskesmas Baringin B, Dinas Kesehatan Rantau, ataupun kelompok pertanian terkait penyuluhan kepada petani tentang manfaat penggunaan APD serta bahaya yang dapat ditimbulkan akibat tidak menggunakan APD.

\section{DAFTAR PUSTAKA}

Afrianto, Defri. 2014. Pengaruh penyuluhan terhadap pengetahuan, sikap dan tindakan petani paprika di desa KumboPasuruan terkait penggunaan alat pelindung diri (APD) dari bahaya pestisida tahun 2014. Skripsi. Jakarta: Universitas Islam Negeri Syarif Hidayatullah. [online] http:// repository.uinjkt.ac.id

Aprinias. 2009. Penggunaan Pestisida. [online]. http:// aprinias.blogspot.co.id/search/label/ PenggunaanPestisida

Djojosumarto, Panut. 2008. Pestisida \& Aplikasinya. Tangerang: PT Agromedia Pustaka.

Kusuma, Reza Yuda. 2013. Hubungan Antara Pengetahuan, Sikap, Dan Kenyamanan Dengan Penggunaan Alat Pelindung Wajah Pada Pekerja Las Listrik Kawasan Simongan Semarang. Skripsi. Semarang: Universitas Negeri Semarang. [online]. http://lib.unnes.ac.id

Notoatmodjo, Soekidjo. 2003. Pendidikan Dan Perilaku Kesehatan. Jakarta: Rineka Cipta

Prijanto, Teguh Budi. 2009. Analisis Faktor Risiko Keracunan Pestisida Organofosfat Pada Keluarga Petani Hortikultura Di Kecamatan Ngablak Kabupaten Magelang. Tesis. Semarang: Universitas Diponegoro. [online]. https:// core.ac.uk

Robbins, S. P. 1998. Organizational behavior: Concepts, Controversies, applications (8th ed). Upper Sadlle River, NJ: Prentice-Hall. http://eprints.ums.ac.id

Sularti. Muhlisin, A. 2012. Hubungan tingkat pengetahuan bahaya pestisida dan kebiasaan pemakaian alat pelindung diri dilihat dari munculnya tanda gejala keracunan pada kelompok tani di Karanganyar. Hal. 154-164. [online]. https://publikasiilmiah.ums.ac.id

Wekoyla. 2012. Hubungan Pengetahuan, Sikap, Pendidikan, Dan Masa Kerja Ter- 
hadap Perilaku Penggunaan Alat Pelindung Diri Pada Tindakan Pertolongan Persalinan Di Rumah Sakit Umum Provinsi Sulawesi Tenggara Dan Rumah Sakit Umum Kota Kendari Tahun 2012. Skripsi. Depok: Universitas Indonesia. [online]. http://lib.ui.ac.id

Yulianto, Endro Hari. 2012. Faktor-Faktor Yang Berhubungan Dengan Penggunaan Alat Pelindung Diri (APD) Pada Petani Dalam Menyemprot Hama Di Desa Doplang Kecamatan Jati Kabupaten Blora. Skripsi. [online]. https:// core.ac.uk 
LAMPIRAN

Tabel 1. Analisis Hubungan Pengetahuan Dengan Penggunaan APD

Pada Petani Pengguna Pestisida

\begin{tabular}{|c|c|c|c|c|c|c|c|}
\hline \multirow[t]{3}{*}{ Pengetahuan } & \multicolumn{5}{|c|}{ Penggunaan APD } & \multirow{3}{*}{$\begin{array}{c}\text { Total } \\
\\
\%\end{array}$} & \multirow{3}{*}{$\begin{array}{c}p-(\text { value }) \\
0,194\end{array}$} \\
\hline & \multicolumn{2}{|c|}{ Tidak menggunakan } & \multicolumn{3}{|c|}{ Menggunakan } & & \\
\hline & $\mathrm{n}$ & $\%$ & $\mathrm{n}$ & $\%$ & $\mathrm{n}$ & & \\
\hline Cukup & 10 & 83,3 & 2 & 16,7 & 12 & 100 & \\
\hline Baik & 40 & 58,8 & 28 & 41,2 & 68 & 100 & \\
\hline Total & 50 & 62,5 & 30 & 37,5 & 80 & $\begin{array}{c}10 \\
0\end{array}$ & \\
\hline
\end{tabular}

Sumber : Data Primer, 2016

Tabel 2. Analisis Hubungan Sikap Dengan Penggunaan APD Pada Petani Pengguna Pestisida Di Desa Candi Laras

\begin{tabular}{|c|c|c|c|c|c|c|c|}
\hline \multirow[t]{3}{*}{ Sikap } & \multicolumn{4}{|c|}{ Penggunaan APD } & \multicolumn{2}{|c|}{ Total } & \multirow{3}{*}{$\begin{array}{c}p-(\text { value }) \\
0,288\end{array}$} \\
\hline & \multicolumn{2}{|c|}{ Tidak menggunakan } & \multicolumn{2}{|c|}{ Menggunakan } & & & \\
\hline & $\mathbf{n}$ & $\%$ & $\mathbf{n}$ & $\%$ & $\mathbf{n}$ & $\%$ & \\
\hline Negatif & 3 & 100 & 0 & 0 & 3 & 100 & \\
\hline Positif & 47 & 61,0 & 30 & 39,0 & 77 & 100 & \\
\hline Total & 50 & 62,5 & 30 & 37,5 & 80 & $\begin{array}{c}10 \\
0\end{array}$ & \\
\hline
\end{tabular}

Sumber : Data Primer, 2016

Tabel 3. Hubungan Status Ekonomi Dengan Penggunaan APD pada Petani Pengguna Pestisida di Desa Candi Laras

\begin{tabular}{|c|c|c|c|c|c|c|c|c|}
\hline \multirow{3}{*}{$\begin{array}{l}\text { Status } \\
\text { Ekonomi }\end{array}$} & \multicolumn{4}{|c|}{ Penggunaan APD } & & & \multirow[b]{2}{*}{$p$-(value $)$} & \multirow[t]{2}{*}{ OR (95\% CI) } \\
\hline & \multicolumn{2}{|c|}{$\begin{array}{c}\text { Tidak } \\
\text { menggunakan }\end{array}$} & \multicolumn{2}{|c|}{ Menggunakan } & \multicolumn{2}{|c|}{ Total } & & \\
\hline & n & $\%$ & $\mathbf{n}$ & $\%$ & $\mathbf{n}$ & $\%$ & 0,002 & $4,442(1,691-$ \\
\hline Rendah & 36 & 76,6 & 11 & 23,4 & 47 & 100 & & $11,666)$ \\
\hline Tinggi & 14 & 42,4 & 19 & 57,6 & 33 & 100 & & \\
\hline Total & 50 & 62,5 & 30 & 37,5 & 80 & 1 & & \\
\hline
\end{tabular}

Sumber : Data Primer, 2016

Tabel 4. Hubungan Masa Kerja Dengan Penggunaan APD pada Petani Pengguna Pestisida di Desa Candi Laras

\begin{tabular}{|c|c|c|c|c|c|c|c|}
\hline \multirow[t]{3}{*}{ Masa Kerja } & \multicolumn{4}{|c|}{ Penggunaan APD } & \multicolumn{2}{|c|}{ Total } & \multirow{3}{*}{$\begin{array}{c}p-(\text { value }) \\
0,678\end{array}$} \\
\hline & \multicolumn{2}{|c|}{$\begin{array}{c}\text { Tidak } \\
\text { menggunakan }\end{array}$} & \multicolumn{2}{|c|}{ Menggunakan } & & & \\
\hline & $\mathbf{n}$ & $\%$ & $\mathbf{n}$ & $\%$ & $\mathbf{n}$ & $\%$ & \\
\hline Baru & 12 & 66,7 & 6 & 33,3 & 18 & 100 & \\
\hline Lama & 38 & 61,3 & 24 & 38,7 & 62 & 100 & \\
\hline Total & 50 & 62,5 & 30 & 37,5 & 80 & $\begin{array}{c}10 \\
0\end{array}$ & \\
\hline
\end{tabular}

Sumber : Data Primer, 2016 